\title{
Oral focal mucinosis arising on the gingiva of orthodontic patient
}

\author{
Alexandre Simões Garcia ${ }^{1}$, Diego Mauricio Bravo-Calderón ${ }^{1}$, Milena Souza Gomes da Costa ${ }^{2}$, \\ Denise Tostes Oliveira $^{1^{*}}$ \\ ${ }^{1}$ Department of Stomatology, Area of Pathology, Bauru School of Dentistry, University of São Paulo, Bauru, Brazil \\ ${ }^{2}$ Private Practice, Franca, Brazil \\ Email: alexsg@fob.usp.br, ․․tostes@fob.usp.br
}

Received 22 August 2012; revised 24 September 2012; accepted 5 October 2012

\begin{abstract}
Oral focal mucinosis is an uncommon non-neoplastic lesion of unknown etiology. We presented a unique case of a sessile, well-demarcated gingival nodule adjacent to the right mandibular first molar of a young girl submitted to orthodontic treatment that was diagnosed as oral focal mucinosis. The probably etiopathogenesis of this lesion in orthodontic patient is discussed.
\end{abstract}

Keywords: Mucinosis; Gingival Diseases; Hyaluronic Acid

\section{INTRODUCTION}

Oral focal mucinosis (OFM) is a type of mucinoses, with unknown etiology, characterized by focal submucosal mucin deposition [1-4]. This lesion occurs as asymptomatic, elevated nodular swelling that may be either pedunculated or sessile [4-6]. Although OFM has been found in various oral sites, there is a predilection for the mandibular gingiva or palate $[3,5]$.

Clinically, because its rarity, this lesion is often diagnosis such as inflammatory fibrous hyperplasia, fibroma or mucocele. The diagnosis of OFM must be based on the histopathological features, classically showing wellcircumscribed myxomatous mesenchymal tissue with stellate fibroblasts [1,6-9].

This is the first case of oral focal mucinosis arising on the gingiva adjacent to molar tooth of a young girl submitted to orthodontic treatment. In addition, we will discussed the probably etiopathogenesis of this condition in orthodontic patient.

\section{CASE REPORT}

A female patient under orthodontic treatment reported a

${ }^{*}$ Corresponding author. painless swelling on the gingiva adjacent to the right mandibular first molar. The lesion had been present for two months and developed after the bonded of an orthodontic tube to the buccal surface of the molar tooth. Intraoral examination revealed a reddish, sessile, firm, well-defined nodule with about $1.0 \mathrm{~cm}$ in greatest dimension (Figure 1). Radiographic examination showed no alterations neither in the underlying bone or in the adjacent teeth. Presumptive clinical diagnosis was inflammatory fibrous hyperplasia or peripheral giant cells lesion. The orthodontic appliance of the 46 tooth was completely removed prior the surgical excision of the lesion. The surgical specimen was sent to the Bauru School of Dentistry Oral Pathology Biopsy Service of the University of São Paulo.

Gross examination revealed a soft tissue mass measuring $0.9 \times 0.5 \times 0.5 \mathrm{~cm}$. The histopathologycal analysis revealed a well-demarcated but not encapsulated area of myxoid tissue with elongated or stellate fibroblasts and small blood vessels (Figure 2). The overlying mucosa composed by stratified squamous ephitelium was unremarkable. The lesion was positive for Alcian Blue, $\mathrm{pH}$ 2.5 (Figure 3). Based on microscopic findings the final diagnosis was oral focal mucinosis. After 1 year followup, the patient showed no signs of recurrence.

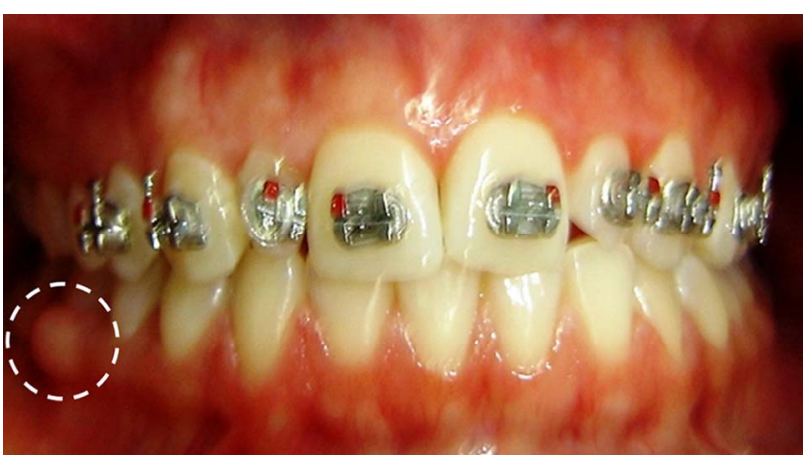

Figure 1. Front view of the orthodontic patient with a welldemarcated, sessile gingival nodule adjacent to the right mandibular first molar (circle). 


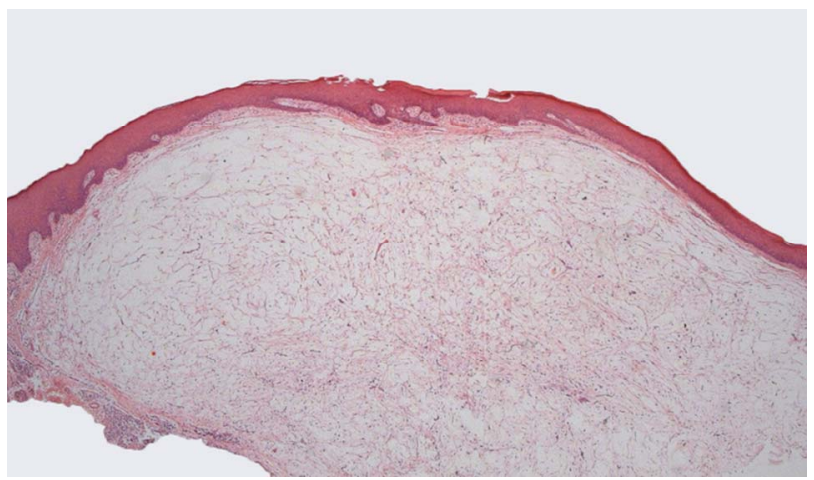

Figure 2. Photomicrograph showing oral epithelium and a well-demarcated but not encapsulated area of myxoid tissue (Hematoxylin and eosin-25×).

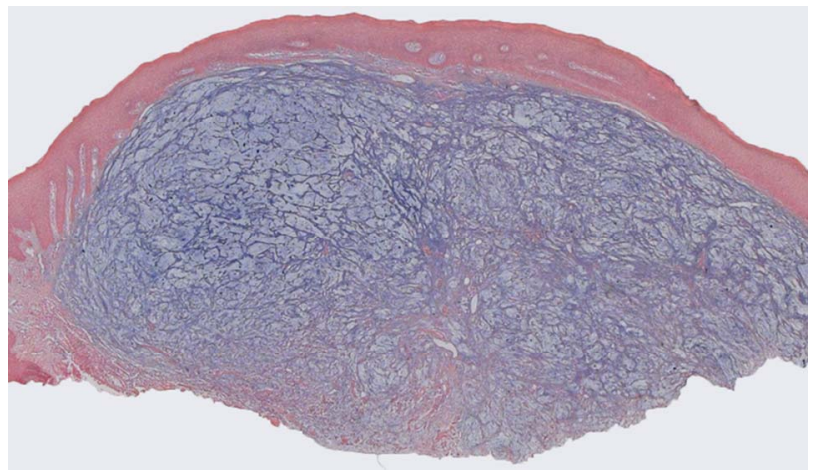

Figure 3. Strong positivity of the myxoid area for Alcian Blue confirming that the lesion is composed by hyaluronic acid (Alcian blue $\mathrm{pH} 2.5-25 \times$ ).

\section{DISCUSSION}

Oral focal mucinosis is an uncommon non-neoplastic lesion considered the oral counterpart of cutaneous focal mucinosis [1]. The pathogenesis of these focal lesions is primarily attributed to an overproduction of hyaluronic acid by fibroblasts at expense of protein production, with subsequent replacement of most of the collagen $[6,8,10]$. However, the etiology of this overproduction of hyaluronic acid is poorly known. According with Reed et al. [11] and with some reported cases, including cases with oral localization $[4,8,10]$, local trauma/inflammation plays a pivotal causative role, being thus OFM considered a reactive process rather than a neoplastic lesion.

In this context, we suggested that in our orthodontic patient, the development of OFM was, probably, induced by bacterial plaque accumulation, after the placement of the orthodontic tube, associated with the orthodontic movement causing a local inflammatory process in the gingival area. However, the real reason why the human fibroblasts of a specific gingival area produce more hyaluronic acid than collagen fibers, as in the present case of OFM, was not yet elucidated [1,9].

Although clinically indistinguishable from the com- mon fibrous oral gingival swellings, the OFM is a distinct entity, with specific histological features. Microscopically, the lesion shows a well-demarcated myxoid area characterized by asymptomatic deposition of hyaluronic acid produced by fibroblast in the oral submucosa as showed in the Figures 2 and 3 . In contrast to focal areas of myxomatous connective tissue found in different oral lesions such as fibrous hyperplasia, peripheral ossifying fibroma and peripheral odontogenic neoplasms, the OFM occurs as a primary myxomatous clinical condition.

Based in the English literature, most cases of OFM occurs in adult women (62\%), being that the lesions have slight predilection for the keratinized mucosa directly overlying bone, particularly the gingiva (70\% of the cases described). Furthermore, large case series have considered the surgical treatment as curative, with evidence of recurrence documented only in one case $[3,5]$. The features of the present case reported confirm the aforementioned findings, however, this is the unique case of OFM documented in orthodontic patient.

Despite of OFM is an uncommon non-neoplastic lesion, the present case report reinforces that it should be considered in the differential diagnosis of nodular gingival lesions of patients under orthodontic therapy.

\section{ACKNOWLEDGEMENTS}

The authors would like to thank Fátima Aparecida Silveira Camargo for technical support. This study was supported by Conselho Nacional de Desenvolvimento Científico e Tecnológico (CNPq—grants \#500991/ 2010-3 and \#142790/2011-7).

\section{REFERENCES}

[1] Tomich, C.E. (1974) Oral focal mucinosis. A clinicopathologic and histochemical study of eight cases. Oral Surgery, Oral Medicine, Oral Pathology and Oral Radiology, 38, 714-724. doi:10.1016/0030-4220(74)90392-2

[2] Iezzi, G., Rubini, C., Fioroni, M. and Piattelli, A. (2001) Oral focal mucinosis of the gingiva: Case report. Journal of Periodontology, 72, 1100-1102. doi:10.1902/jop.2001.72.8.1100

[3] Soares de Lima, A.A., Naval Machado, M.A., Martins, W.D., Trindade Gregio, A.M., Dirschnabel, A.J., Folador Mattioli, T.M., et al. (2008) Oral focal mucinosis. Quintessence International, 39, 611-615.

[4] Madhusudhan, A.S., Nagarajappa, D., Manjunatha, B.S., Saawarn, S. and Charan Babu, H.S. (2010) Oral focal mucinosis: Report of two cases. Revista Odonto Ciência, 25, 310-313.

[5] Narayana, N. and Casey, J. (2009) Oral focal mucinosis: Review of the literature and seven additional cases. General Dentistry, 57, e11-e13.

[6] Buchner, A., Merrell, P.W., Leider, A.S. and Hansen, L.S. 
(1990) Oral focal mucinosis. International Journal of Oral and Maxillofacial Surgery, 19, 337-340. doi:10.1016/S0901-5027(05)80076-1

[7] Saito, I., Ide, F., Enomoto, T. and Kudo I. (1985) Oral focal mucinosis. Journal of Oral and Maxillofacial Surgery, 43, 372-374. doi:10.1016/0278-2391(85)90259-9

[8] Gabay, E., Akrish, S. and Machtei, E.E. (2010) Oral focal mucinosis associated with cervical external root resorption: A case report. Oral Surgery, Oral Medicine, Oral Pathology, Oral Radiology and Endodontics, 110, e75e78. doi:10.1016/j.tripleo.2010.04.002
[9] Lee, J.G., Allen, G., Moore, L. and Gue, S. (2012) Oral focal mucinosis in an adolescent: A case report. Australian Dental Journal, 57, 90-92. doi:10.1111/j.1834-7819.2011.01649.x

[10] Gnepp, D.R., Vogler, C., Sotelo-Avila, C. and Kielmovitch, I.H. (1990) Focal mucinosis of the upper aerodigestive tract in children. Human Pathology, 21, 856-858. doi:10.1016/0046-8177(90)90056-B

[11] Reed, R.J., Clark, W.H. and Mihm, M.C. (1973) The cutaneous mucinoses. Human Pathology, 4, 201-205. doi:10.1016/S0046-8177(73)80007-3 